https://helda.helsinki.fi

\title{
Cytochrome P450 in Pharmacogenetics: An Update
}

\section{Tornio, A.}

2018

Tornio , A \& Backman , J T 2018 , ' Cytochrome P450 in Pharmacogenetics: An Update ' , Advances in Pharmacology, vol. 83 , pp. 3-32 . https://doi.org/10.1016/bs.apha.2018.04.007

http://hdl.handle.net/10138/300396

https://doi.org/10.1016/bs.apha.2018.04.007

acceptedVersion

Downloaded from Helda, University of Helsinki institutional repository.

This is an electronic reprint of the original article.

This reprint may differ from the original in pagination and typographic detail.

Please cite the original version. 


\section{Running Title:}

CYPs in pharmacogenetics

\section{Title:}

Cytochrome P450 in pharmacogenetics: an update

\section{Authors:}

Aleksi Tornio, and Janne T. Backman

\section{Affiliation:}

Department of Clinical Pharmacology, University of Helsinki and Helsinki University Hospital, Helsinki, Finland

\section{Corresponding author contact information:}

Professor Janne T. Backman, MD

Department of Clinical Pharmacology

University of Helsinki and Helsinki University Hospital, PO Box 705, FI-00029 HUS, Finland

Fax: +358-9-471 74039

Tel. $+358-50-4280997$

E-mail: janne.backman@helsinki.fi 


\begin{abstract}
Interindividual variability in drug disposition is a major cause of lack of efficacy and adverse effects of drug therapies. The majority of hepatically cleared drugs are metabolized by cytochrome P450 (CYP) enzymes, mainly in families CYP1, CYP2, and CYP3. Genes encoding these enzymes are highly variable with allele distribution showing considerable differences between populations. Genetic variability of especially $C Y P 2 C 9, C Y P 2 C 19, C Y P 2 D 6$, and $C Y P 3 A 5$ is known to have clear clinical impact on drugs that are metabolized by these enzymes. CYP1A2, CYP2A6, CYP2B6, $C Y P 2 C 8$, and $C Y P 3 A 4$ all show variability that affects pharmacokinetics of drugs as well, but so far the evidence regarding their clinical implications is not as conclusive. In this review, we provide an up-to-date summary of the pharmacogenetics of the major human drug-metabolizing CYP enzymes, focusing on clinically significant examples.
\end{abstract}

\title{
Keywords
}

CYP2C9, CYP2C19, CYP2D6, Cytochrome P450, Drug metabolism, Pharmacogenetics, Pharmacokinetics 


\section{Nonstandard abbreviations}

AhR aryl hydrocarbon receptor

AS activity score

CNV copy-number variant

CPIC Clinical Pharmacogenetics Implementation Consortium

CYP cytochrome P450

DPWG Dutch Pharmacogenetics Working Group

IM intermediate metabolizer

IWPC International Warfarin Pharmacogenetics Consortium

MAF minor allele frequency

NM normal metabolizer

PM poor metabolizer

PPI proton pump inhibitor

SNV single-nucleotide variant

SSRI selective serotonin reuptake inhibitor

TCA tricyclic antidepressant

UM ultrarapid metabolizer

VKORC1 vitamin K epoxide reductase complex subunit 1 


\section{Introduction}

The cytochrome P450 (CYP) enzymes are a superfamily of hemoproteins, which have crucial functions in the metabolism of both endogenous and xenobiotic compounds. In humans, 57 putatively functional genes and 58 pseudogenes have been described (Nelson, Zeldin, Hoffman, Maltais, Wain, $\&$ Nebert, 2004). Most of the genes, which are divided into 18 families and 44 subfamilies based on their sequence similarity, have endogenous roles such as metabolism of bile acids, eicosanoids and steroids (Nebert \& Russell, 2002). Only about a dozen CYP enzymes belonging to families CYP1, CYP2 and CYP3 are important for drug metabolism (Table 1). However, the majority of clinically used drugs are metabolized by CYP enzymes (Zanger, Turpeinen, Klein, \& Schwab, 2008), and many drugs are predominantly metabolized by a single CYP enzyme at clinically relevant concentrations in humans. Thus, intrinsic and extrinsic factors that influence CYP enzyme activity can have important effects on pharmacokinetics of drugs. For some drug-metabolizing CYP enzymes, in particular CYP2C9, CYP2C19, and CYP2D6, genetic variability explains a large proportion of variability in enzyme activity, whereas for some other CYPs, such as CYP1A2, and CYP3A4, this proportion is much smaller (Zanger \& Schwab, 2013). This review highlights the current knowledge on the pharmacogenetics of drug-metabolizing CYP enzymes, as well as its clinical relevance.

\section{Genetic variability of CYP enzymes}

The drug-metabolizing CYP enzymes are genetically highly variable, in part due to low evolutionary constraint as many of them lack essential endogenous function. The variability is characterized by common and rare single-nucleotide variants (SNVs), as well as copy-number variants (CNVs), defined as duplications or deletions. The variants of CYP genes are defined by star (*) allele nomenclature for which the Human Cytochrome P450 (CYP) Allele Nomenclature Database has served as a central repository for over 15 years. The database has recently been transitioned to be managed by the Pharmacogene Variation (PharmVar) Consortium available at www.PharmVar.org 
(Gaedigk, Ingelman-Sundberg, Miller, Leeder, Whirl-Carrillo, Klein et al., 2017). The functional status of the variant alleles can range from no function to increased function, and thus phenotypes ranging from poor metabolizer (PM) to ultrarapid metabolizer (UM) can be inferred from the genotype (Table 2). In order to standardize the terminology used to describe allele functional status and phenotype, a consensus paper was published by Clinical Pharmacogenetics Implementation Consortium (CPIC) (Caudle, Dunnenberger, Freimuth, Peterson, Burlison, Whirl-Carrillo et al., 2017). Lastly, to facilitate the transformation of pharmacogenetic knowledge into clinical practice and to provide evidence-based guidelines on how available genetic test results should be used to optimize drug therapy, several consortia have been established. Both CPIC and the Dutch Pharmacogenetics Working Group (DPWG) provide genotype-based dosing guidelines based on gene-drug pairs, with some differences in guideline development methods and the number of guidelines produced so far (Bank, Caudle, Swen, Gammal, Whirl-Carrillo, Klein et al., 2017).

\section{CYP1A subfamily}

\subsection{CYP1A2}

CYP1A2 belongs to the CYP1 family and its gene is located on chromosome 15 along with CYP1A1 and CYP1B1. Their expression is regulated by the aryl hydrocarbon receptor (AhR) pathway. CYP1A2 is abundantly expressed in the liver (Zhang, Wang, Gao, Wei, Tian, Zhao et al., 2016) and it is involved in the metabolism of about $10 \%$ of clinically used drugs that are metabolized by CYP enzymes (S. F. Zhou, Wang, Yang, \& Liu, 2010). In contrast, CYP1A1 and CYP1B1 are mostly extrahepatic, and are of lesser importance for drug metabolism. CYP1A2 is involved in the metabolism of e.g., agomelatin, caffeine, clozapine, duloxetine, propranolol, tizanidine and zolmitriptan, as well as some endogenous compounds, such as melatonin and estradiol. CYP1A2 activity is strongly affected by environmental factors. AhR mediated induction by smoking or food 
components can markedly increase CYP1A2 activity. In contrast, oral contraceptives, fluoroquinolones, and fluvoxamine inhibit CYP1A2 to a clinically relevant degree.

Several SNVs have been identified that affect CYP1A2 function, but they only partially explain the variability in enzyme activity (Gunes \& Dahl, 2008). The most common variants are located in the $5^{\prime}$ flanking region, including $C Y P 1 A 2 * 1 F$ (defining variant rs762551, g.-163C $>$ A) which has a high frequency in many populations (Y. Zhou, Ingelman-Sundberg, \& Lauschke, 2017). On the other hand, nonsynonymous coding variants $(C Y P 1 A 2 * 2$ to $* 21)$ are rare. Caffeine is frequently used to probe CYP1A2 activity, as caffeine N3-demethylation to paraxanthine is selectively catalyzed by CYP1A2 (Fuhr, Rost, Engelhardt, Sachs, Liermann, Belloc et al., 1996). CYP1A2 and AhR loci have been identified in several genomewide association studies to be linked with habitual coffee consumption (Amin, Byrne, Johnson, Chenevix-Trench, Walter, Nolte et al., 2012; Coffee and Caffeine Genetics ConsortiumCornelisByrneEskoNallsGanna et al., 2015; Cornelis, Monda, Yu, Paynter, Azzato, Bennett et al., 2011). CYP1A2*1F has been associated in many studies with increased inducibility of CYP1A2 by e.g., smoking (Sachse, Brockmoller, Bauer, \& Roots, 1999), but otherwise its functional consequence is less clear. In any case, genetic effects on CYP1A2 activity might be masked by environmental factors, in particular by smoking and oral contraceptive use (Matthaei, Tzvetkov, Strube, Sehrt, Sachse-Seeboth, Hjelmborg et al., 2016), and the conclusions thus can depend on the population studied. Furthermore, earlier studies including only single variants might have missed more complex haplotypes including several variants. Taken together, the current available evidence does not support CYP1A2 genotype-based dosing for any drug. 


\section{CYP2A and CYP2B subfamilies}

\subsection{CYP2A6}

CYP2A6 represents about $4 \%$ of total hepatic microsomal CYP enzyme content, and it is also expressed in some extrahepatic tissues, such as lungs and trachea (Di, Chow, Yang, \& Zhou, 2009; Ding \& Kaminsky, 2003; Zhang et al., 2016). In comparison to other CYP enzymes, CYP2A6 has a small active site (Yano, Hsu, Griffin, Stout, \& Johnson, 2005). It has a major role in the metabolism of coumarin, letrozole, nicotine, and tegafur, and it contributes to the metabolism of other drugs, such as artemisin, efavirenz, halothane, pilocarpine, and valproic acid.

CYP2A6 gene is highly variable, with over 40 star alleles described to date, along with additional suballeles (https://www.pharmvar.org/gene/CYP2A6, accessed 5 February 2018). The spectrum of $C Y P 2 A 6$ variant alleles include SNVs (e.g., $\left.C Y P 2 A 6^{*} 2, * 6\right)$, gene deletions (e.g., *4A$H$ ), a hybrid gene with CYP2A7 (e.g., *3, *12A-C), and gene conversions (e.g., *1B1-17) (McDonagh, Wassenaar, David, Tyndale, Altman, Whirl-Carrillo et al., 2012). In principle, CYP2A6 phenotype, ranging from poor to ultrarapid metabolizer, can be inferred from CYP2A6 genotype. However, the effects of CYP2A6 variant alleles are known to be substrate specific (Fukami, Nakajima, Higashi, Yamanaka, Sakai, McLeod et al., 2005), and due to the high number of different variants and complex genetic architecture, variant allele carriers may be misclassified as e.g., wildtype due to limitations in genotyping methods used (Hoffman, Nelson, \& Keeney, 2001). In addition, the distribution of variant alleles varies greatly between populations (Y. Zhou et al., 2017). The decreased function allele $C Y P 2 A 6^{*} 9$ is common in all major populations (minor allele frequency (MAF) ranging from $8 \%$ in Africans to $23 \%$ in East Asians), whereas $C Y P 2 A 6^{*} 17, C Y P 2 A 6^{*} 23$, $C Y P 2 A 6^{*} 25$, and $C Y P 2 A 6^{*} 28$ are only found in Africans, and $C Y P 2 A 6^{*} 7$, and $C Y P 2 A 6^{*} 19$ in East Asians. In Europeans, the most common variant alleles leading to decreased function are $C Y P 2 A 6^{*}$, and $C Y P 2 A 6^{*} 35$ with MAFs of $11 \%$ and $15 \%$, respectively. 
The metabolism of nicotine to cotinine is strongly related to CYP2A6 activity, and CYP2A6 variants largely explain inter-individual variability in the metabolism of nicotine to cotinine (Bloom, Hinrichs, Wang, von Weymarn, Kharasch, Bierut et al., 2011; Hukkanen, Jacob, \& Benowitz, 2005). CYP2A6 variant alleles associated with reduced nicotine metabolism have been linked with lesser likelihood of becoming smoker, lower cigarette consumption, and better ability to quit than normal metabolizers in many studies (McDonagh et al., 2012; Ray, Tyndale, \& Lerman, 2009).

CYP2A6 is involved in the bioactivation of tegafur to 5-fluorouracil, and genetic variation of CYP2A6 has been associated with altered tegafur metabolism, and also clinical outcomes in some studies (Kaida, Inui, Suda, Nakamura, Watanabe, \& Chida, 2008; Kong, Lim, Nam, Kook, Kim, Ryu et al., 2009; Park, Kong, Nam, Choi, Kim, Lee et al., 2011). These results suggest that bioactivation of tegafur is impaired in CYP2A6 poor metabolizers, but the associations with clinical endpoints have not been replicated in all studies, and they may be dependent on the cancer type and combination treatment given (Tanner \& Tyndale, 2017). In addition, decreased function alleles of CYP2A6 have been associated with increased plasma concentrations of another anticancer agent, letrozole (Desta, Kreutz, Nguyen, Li, Skaar, Kamdem et al., 2011; Tanii, Shitara, \& Horie, 2011). It remains to be determined, however, whether the genotype has an impact on the efficacy and side effects of letrozole. In addition, $C Y P 2 A 6$ variants have been reported to have an influence on the pharmacokinetics of efavirenz and valproic acid, even though other enzymes contribute the elimination of these drugs (Tanner \& Tyndale, 2017).

\subsection{CYP2B6}

Similarly to CYP2A6, the expression of CYP2B6 is highly variable, and it represents only a small percentage of the total hepatic microsomal CYP content (H. Wang \& Tompkins, 2008; Zhang et al., 
2016). $C Y P 2 B 6$ and $C Y P 2 A 6$ are located in close proximity in chromosome 19 , and their expression levels are correlated (A1 Koudsi \& Tyndale, 2010). In addition to the liver, CYP2B6 is also expressed in the brain (Miksys \& Tyndale, 2004). It is involved in the metabolism of e.g., bupropion, cyclophosphamide, efavirenz, methadone, and nevirapine (Turpeinen \& Zanger, 2012; H. Wang \& Tompkins, 2008).

Currently, 38 CYP2B6 variants with designated star alleles are described (https://www.pharmvar.org/gene/CYP2B6, accessed 5 February 2018). The most widely studied allele is $C Y P 2 B 6^{*} 6,(\mathrm{c} .516 \mathrm{G}>\mathrm{T}, \mathrm{c} .785 \mathrm{~A}>\mathrm{G})$ resulting in reduced expression, which is found with a MAF of 3\% in Europeans, $6 \%$ in Africans, 3\% in East Asians, $16 \%$ in South Asians, and 3\% in admixed Americans (Y. Zhou et al., 2017). The most common variant allele in all major populations is $C Y P 2 B 6^{*} 9$ (c.516G $\left.>\mathrm{T}\right)$, but its functional significance is less clear. Alleles with increased function have also been described $\left(C Y P 2 B 6^{*} 4\right.$ and $\left.C Y P 2 B 6^{*} 22\right)$, with a MAF of $<2 \%$ in most major populations, with the exception of $C Y P 2 B 6^{*} 22$ with a MAF of about $4 \%$ in Africans.

The nonnucleoside reverse transcriptase inhibitor efavirenz is metabolized predominantly by CYP2B6. Several studies have shown an association between $C Y P 2 B 6$ genotype, in particular the reduced function $C Y P 2 B 6^{*} 6$ allele, and efavirenz related adverse effects including central nervous system toxicity and hepatotoxicity (Vo \& Varghese Gupta, 2016). On the other hand, the effect on clinical outcomes has not been as widely replicated. Genotype-based dose reduction of efavirenz in CYP2B6 poor metabolizers has been performed in some studies (Gatanaga, Hayashida, Tsuchiya, Yoshino, Kuwahara, Tsukada et al., 2007). Interestingly, even though CYP2A6 is a minor metabolic pathway for efavirenz in general, $C Y P 2 A 6^{*} 9$ has been associated with increased efavirenz plasma concentrations in CYP2B6 poor metabolizers (Haas, Kwara, Richardson, Baker, Papageorgiou, Acosta et al., 2014). To date, no genotype-based dosing guideline has been published, but efavirenz is a potential candidate for such a guideline with emerging evidence. 
$C Y P 2 B 6^{*} 6$ has been associated with reduced metabolism of bupropion, a pro-drug which is activated by CYP2B6. The effect of $C Y P 2 B 6 * 6$ allele on the efficacy of bupropion on smoking cessation has been shown in some, but not all, studies (Chenoweth \& Tyndale, 2017; Lee, Jepson, Hoffmann, Epstein, Hawk, Lerman et al., 2007; Zhu, Cox, Nollen, Faseru, Okuyemi, Ahluwalia et al., 2012)). Pharmacokinetics of several other CYP2B6 substrates, such as cyclophosphamide, methadone and nevirapine have been reported to be influenced by CYP2B6 genotype, but evidence regarding them is not yet conclusive (Zanger \& Klein, 2013).

\section{CYP2C subfamily}

The CYP2C subfamily consists of four highly homologous genes CYP2C18-CYP2C19-CYP2C9CYP2C8, which are located in this order from centromere to telomere on chromosome 10q23.33. Even though CYP2C18 mRNA is highly expressed in the liver, it does not get efficiently translated into protein (Läpple, von Richter, Fromm, Richter, Thon, Wisser et al., 2003). The other CYP2C enzymes are expressed in the liver in the order CYP2C9 $>$ CYP2C8 $>$ CYP2C19, and, to a lesser extent, in the small intestine (Zhang et al., 2016). CYP2C enzyme activities can be markedly altered by environmental factors. A variety of xenobiotics such as rifampicin, and hyperforin can induce the transcriptional expression of CYP2C genes in hepatocytes and thereby increase the metabolism of CYP2C substrates. Several drug-activated nuclear receptors including CAR, PXR, VDR, and GR have been implicated in this induction (Chen \& Goldstein, 2009). Many drugs can also act as reversible or time-dependent inhibitors of CYP2C enzymes, such as clopidogrel and gemfibrozil for CYP2C8, fluconazole and miconazole for CYP2C9, and fluvoxamine and omeprazole for CYP2C19.

\subsection{CYP2C8}

CYP2C8 has been established as one of the key drug-metabolizing CYP enzymes during the last 15 years (Backman, Filppula, Niemi, \& Neuvonen, 2016). CYP2C8 metabolizes a variety of xenobiotics 
and drugs, including amodiaquine, dasabuvir, imatinib, paclitaxel, loperamide, montelukast, pioglitazone, repaglinide, and rosiglitazone, for example.

There are tens of SNVs, short deletions and essential splice site variants that have been found in the CYP2C8 gene. Fourteen CYP2C8 alleles have a designated star allele (https://www.pharmvar.org/gene/CYP2C8, accessed 31 Jan 2018). The alleles CYP2C8*2, *3 and *4 account for the majority of nonsynonymous variability of CYP2C8 in humans (Y. Zhou et al., 2017). CYP2C8*2 (c.805A $>$ T, p.Ile269Phe; rs 11572103) occurs with an allele frequency ranging from about $10 \%$ to $37 \%$ in individuals with a sub-Saharan African ancestry. However, this allele is rare or absent in most Asian, European and admixed American populations. The $C Y P 2 C 8 * 3$ allele consists of two nonsynonymous variants (c.416G>A, p.Arg139Lys; rs11572080, and c.1196A>G, p.Lys399Arg; rs10509681) that are in complete or nearly complete linkage. CYP2C8*3 is also in linkage disequilibrium with the $C Y P 2 C 9 * 2$ allele (Yasar, Lundgren, Eliasson, Bennet, Wiman, de Faire et al., 2002). In individuals with a European ancestry, the allele frequency of $C Y P 2 C 8 * 3$ approximates $11 \%$ (Y. Zhou et al., 2017). In South Asian and admixed American populations the frequency of the allele is about $4 \%$ and $7 \%$, respectively, while in Sub-Saharan African populations the frequency is generally very low, albeit highly variable. Like $C Y P 2 C 8 * 3$, the $C Y P 2 C 8^{*} 4$ allele (c.792C.G, p.Ile264Met; rs1058930) is more common in European than in other populations. In most populations, its frequency is lower (by a factor of about two) than that of $C Y P 2 C 8^{*} 3$.

The clinical significance of CYP2C8 pharmacogenetics seems to be limited (Backman et al., 2016). Most in vitro studies have suggested that the $C Y P 2 C 8 * 2, * 3$ and $* 4$ alleles result in moderately decreased CYP2C8 function. However, also opposite findings have been reported regarding the $* 3$ and $* 4$ alleles, for example with respect to the metabolism of cerivastatin (Kaspera, Naraharisetti, Tamraz, Sahele, Cheesman, Kwok et al., 2010). Many clinical studies have suggested an increased CYP2C8 activity for carriers of the *3 allele. Individuals with the CYP2C8*1/*3 genotype have had an approximately 40-50\% lower repaglinide AUC than individuals with the 
CYP2C8*1/*1 genotype (Backman et al., 2016). In addition, the AUCs of rosiglitazone or pioglitazone have been about $20-40 \%$ lower in $C Y P 2 C 8^{*} 3$ carriers than in noncarriers, with an apparent gene-dose effect. In accordance with the pharmacokinetic findings, $C Y P 2 C 8^{*} 3$ has been associated with reduced glycemic response to rosiglitazone treatment in two studies in patients with type 2 diabetes mellitus (Dawed, Donnelly, Tavendale, Carr, Leese, Palmer et al., 2016; Stage, Christensen, Feddersen, Beck-Nielsen, \& Brøsen, 2013). Furthermore, in a recent study, CYP2C8*3 carriers $(\mathrm{n}=34)$ had a slightly higher imatinib metabolic ratio than did $C Y P 2 C 8^{*} 1 / * 1(\mathrm{n}=147)$ patients (Barratt, Cox, Menelaou, Yeung, White, Hughes et al., 2017).

In contrast to the clinical findings with repaglinide and thiazolidinediones, the $C Y P 2 C 8 * 3$ allele has been associated with a slightly impaired clearance of paclitaxel (Bergmann, BraschAndersen, Green, Mirza, Pedersen, Nielsen et al., 2011; Henningsson, Marsh, Loos, Karlsson, Garsa, Mross et al., 2005) and an increased risk for paclitaxel-induced neurotoxicity or myelosuppression (Backman et al., 2016; Boora, Kanwar, Kulkarni, Abyzov, Sloan, Ruddy et al., 2016; Lam, Frederiks, van der Straaten, Honkoop, Guchelaar, \& Boven, 2016). Thus, it seems that the influence of CYP2C $8 * 3$ on drug metabolism may be substrate dependent and is usually only modest. Based on limited evidence, $C Y P 2 C 8 * 2$ and $* 4$ alleles appear to have some, but limited, effect on the pharmacokinetics of CYP2C8 substrates. Inactive $C Y P 2 C 8$ alleles, such as $* 5, * 7$ and $* 11$ are rare (Y. Zhou et al., 2017), but as case reports have shown, such alleles can drastically increase the risk of adverse reactions (Backman et al., 2016). At present, there are no genotype-based consensus guidelines for CYP2C8.

\subsection{CYP2C9}

CYP2C9 is one of the most important CYP enzymes in terms of the number of substrates; it has been estimated to contribute to the metabolism of approximately $15 \%$ of all drugs that are 
metabolized by CYP enzymes (Daly, Rettie, Fowler, \& Miners, 2017; Kirchheiner \& Brockmöller, 2005). Important CYP2C9 substrates include warfarin (S-isomer), acenocoumarol, phenytoin, losartan, fluvastatin, bosentan, most sulphonylureas and several nonsteroidal anti-inflammatory agents.

Two nonsynonymous polymorphisms, rs1799853 (c.430C $>$ T, p.Arg144Cys) and rs1057910 (c.1075A $>$ C, p.Ile359Leu), define the $C Y P 2 C 9 * 2$ and $C Y P 2 C 9 * 3$ alleles, respectively (https://www.pharmvar.org/gene/CYP2C9, accessed 31 Jan 2018). They are the best studied alleles largely because they are functionally detrimental and globally the most common $C Y P 2 C 9$ variants. Altogether, there are $60 C Y P 2 C 9$ variants with a star allele name and tens of other single nucleotide variants $(\mathrm{SNVs})$ in the regulatory and coding regions of the $C Y P 2 C 9$ gene. Apart from $C Y P 2 C 9 * 2$ and $C Y P 2 C 9 * 3$, some of the alleles are also relatively common and at least $C Y P 2 C 9 * 5, C Y P 2 C 9 * 6$, $C Y P 2 C 9^{*} 11, C Y P 2 C 9^{*} 12$ and $C Y P 2 C 9^{*} 13$ can produce an enzyme with markedly reduced activity (Daly et al., 2017).

The allele frequencies of $C Y P 2 C 9 * 2$ and $C Y P 2 C 9 * 3$ are around $12 \%$ and $6 \%$ in European subjects (Y. Zhou et al., 2017). CYP2C9*2 is also relatively common in admixed Americans (7\%), South Asians (5\%) and Africans (2\%) but very rare in East Asians, while $C Y P 2 C 9 * 3$ is remarkably common in South Asians (11\%) and fairly common in East Asians and Americans (3-4\%). CYP2C9*3 is generally associated with a more than $80 \%$ reduction in CYP2C9 mediated intrinsic clearance, while the effect of $C Y P 2 C 9 * 2$ is generally slightly smaller and varies considerably, depending on the substrate (Daly et al., 2017). Interestingly, CYP2C9*8 and CYP2C $9 * 9$ are more common $(6 \%$ and $8 \%$ ) than the $* 2$ and $* 3$ alleles in Africans, but extremely rare in Europeans (Y. Zhou et al., 2017). In addition, also $C Y P 2 C 9 * 5, C Y P 2 C 9 * 6$ and $C Y P 2 C 9 * 11$ are much more common among Africans than among Europeans and $C Y P 2 C 9^{*} 14$ is fairly common in South Asians, while all other alleles are rare in major populations. Based on genotypes, individuals can be classified as normal $(* 1 / * 1)$, intermediate (IM, carrier of one decreased-function allele) or poor (carrier of two decreased-function 
alleles) metabolizers (Table 2). About 30\% of Europeans are IMs and $4 \%$ are PMs, and the frequencies of these phenotypes are somewhat lower in other populations (Table 3).

One of the most sensitive drugs to genetic variability in CYP2C9 activity is warfarin, since its S-isomer is metabolized almost exclusively by CYP2C9 (Baker \& Johnson, 2016; Rettie, Korzekwa, Kunze, Lawrence, Eddy, Aoyama et al., 1992). Consequently, the oral clearance of Swarfarin is reduced by 70-85\% in CYP2C9 PMs and about 40\% in IMs, leading to a longer S-warfarin half-life, longer delay in reaching a stable INR, lower warfarin dose requirement, and increased risk of bleeding during warfarin treatment, particularly in PMs (Jorgensen, FitzGerald, Oyee, Pirmohamed, \& Williamson, 2012). Apart from CYP2C9 variants (explain about 6\% to $19 \%$ of variability in dose requirement), a number of other factors contribute to warfarin dose requirement, including vitamin $\mathrm{K}$ epoxide reductase complex subunit 1 (VKORC1) and CYP4F2 genotypes, patient age, body size, smoking status and certain concomitant medications. Various algorithms have been developed to guide warfarin dosing on the basis of these factors. The first algorithm developed on a sufficient patient population was published 10 years ago by Gage et al. (Gage, Eby, Johnson, Deych, Rieder, Ridker et al., 2008) and is currently in use as a modified and updated web-based calculator (www.warfarindosing.org). A large worldwide project, International Warfarin Pharmacogenetics Consortium (IWPC), also developed a definitive warfarin dosing algorithm using clinical and genetic data on about 5000 patients treated with warfarin, including different ethnicities (International Warfarin Pharmacogenetics Consortium, Klein, Altman, Eriksson, Gage, Kimmel et al., 2009).

Three large randomized controlled trials, termed CoumaGen-II, EU-PACT and GIFT, comparing the above warfarin dosing algorithms to various conventional non-genetic approaches suggested that genotype-based dosing can be beneficial when warfarin treatment is initiated (Anderson, Horne, Stevens, Woller, Samuelson, Mansfield et al., 2012; Gage, Bass, Lin, Woller, Stevens, Al-Hammadi et al., 2017; Pirmohamed, Burnside, Eriksson, Jorgensen, Toh, Nicholson et al., 2013). However, in the fourth randomized study, COAG, the time within therapeutic range in the 
first 4 weeks of warfarin treatment was not improved by genotype-based dosing, and the outcome was even worse in the genotyped African-Americans than in the controls (Kimmel, French, Kasner, Johnson, Anderson, Gage et al., 2013). The poor result of the COAG study may be partly explained by that $C Y P 2 C 9$ genotyping included only the $* 2$ and $* 3$ alleles, but not the common African alleles. Accordingly, more comprehensive algorithms have been developed, and the warfarindosing.org website now contains both the Gage algorithm and the IWPC algorithm and enables adjustments for CYP4F2, CYP2C9*5 and *6. The CPIC guideline for pharmacogenetics-guided warfarin dosing and its annotations (https://cpicpgx.org/guidelines/guideline-for-warfarin-and-cyp2c9-and-vkorc1/) provide detailed instructions on how to use pharmacogenetic algorithms for warfarin dosing (Johnson, Caudle, Gong, Whirl-Carrillo, Stein, Scott et al., 2017). Apart from warfarin, CYP2C9 genotype influences to some degree also the pharmacokinetics of the other coumarins acenocoumarol and phenprocoumon.

In addition to anticoagulants, CYP2C9 *2 and *3 alleles can markedly reduce the clearances of sulfonylureas, particularly tolbutamide and glipizide (Kirchheiner \& Brockmöller, 2005). Clinical studies and case reports have suggested that $C Y P 2 C 9$ variant allele carriers are more sensitive to the hypoglycaemic effect of sulfonylureas and may be at risk of hypoglycaemia (Daly et al., 2017). In addition, CYP2C9 variant alleles markedly affect the pharmacokinetics of a number of nonsteroidal anti-inflammatory drugs, including celecoxib, ibuprofen and flurbiprofen. There are also several studies suggesting that $C Y P 2 C 9$ variant carriers are at an increased risk of NSAID-associated gastrointestinal bleeding (Figueiras, Estany-Gestal, Aguirre, Ruiz, Vidal, Carvajal et al., 2016).

The antiepileptic drug phenytoin has a narrow therapeutic index and complex pharmacokinetic characteristics, including saturable metabolism and dependence on CYP2C9 activity (Caudle, Rettie, Whirl-Carrillo, Smith, Mintzer, Lee et al., 2014). Both $C Y P 2 C 9 * 2$ and $C Y P 2 C 9 * 3$ are associated with impaired clearance of phenytoin. Consequently, it has been reported that phenytoin maintenance doses are reduced by about $30 \%$ in heterozygous carriers of these $C Y P 2 C 9$ 
alleles and by $30-50 \%$ in homozygous carriers, compared to noncarriers. Furthermore, case reports suggest that CYP2C9 PMs are at increased risk for dose-related phenytoin toxicities. Accordingly, the respective CPIC guideline recommends a $25-50 \%$ reduction of phenytoin starting maintenance dose in decreased function $C Y P 2 C 9$ allele carriers, with subsequent maintenance doses adjusted based on therapeutic drug monitoring or response (Caudle et al., 2014).

\subsection{CYP2C19}

CYP2C19 participates in the metabolism of many clinically relevant drugs such as benzodiazepines, proton pump inhibitors (PPIs), selective serotonin reuptake inhibitors (SSRIs), tricyclic antidepressants (TCAs) and voriconazole, and it is important for the metabolic activation of the prodrug clopidogrel.

CYP2C19 is highly variable with 35 defined haplotypes with a designated star allele so far (https://www.pharmvar.org/gene/CYP2C19, accessed 14 Jan 2018). The most common no function allele is $C Y P 2 C 19 * 2$ (c.681G $>A$; rs4244285), occurring with an allele frequency of $18 \%$ in Africans and Europeans, and over 30\% in Asian populations (Y. Zhou et al., 2017). Other decreased or no function alleles $(* 3-* 8)$ are typically rare, with the exception of $C Y P 2 C 19 * 3$ (c.636G $>A$; rs4986893) in East Asians with a MAF of about 7\%. On the other hand, the increased function CYP2C19*17 allele (c.-806C $>\mathrm{T}$; rs 12248560$)$ results in enhanced transcription probably due to the modulation of GATA4 binding (Mwinyi, Hofmann, Pedersen, Nekvindova, Cavaco, Mkrtchian et al., 2010). It is common in Europeans and Africans (MAF about 23\%), less common in admixed Americans and South Asians (12-14\%), and almost absent in East Asians. Thus, CYP2C19 phenotype ranges from PM to UM (Table 3).

The clinical significance of CYP2C19 pharmacogenetics is well established. For example, clopidogrel is a prodrug, which is activated in two sequential oxidative steps involving several CYP enzymes, including CYP2C19 (Kazui, Nishiya, Ishizuka, Hagihara, Farid, Okazaki et 
al., 2010). Many studies have indicated that the bioactivation of clopidogrel is impaired in CYP2C19 poor metabolizers and that these PMs have lower levels of clopidogrel active metabolite than normal metabolizers (Scott, Sangkuhl, Stein, Hulot, Mega, Roden et al., 2013). Moreover, there is substantial evidence linking CYP2C19 genotype with clinical outcomes, especially in patients with acute coronary syndrome who have undergone percutaneous coronary intervention (Mao, Jian, Changzhi, Dan, Suihua, Wenyi et al., 2013; Mega, Simon, Collet, Anderson, Antman, Bliden et al., 2010). More recently, a meta-analysis of clopidogrel-treated patients with stroke or transient ischemic attack suggested a similar level of risk for vascular events than that reported for patients with coronary artery disease (Y. Pan, Chen, Xu, Yi, Han, Yang et al., 2017), and the risk seems to be attenuated in stroke patients treated with clopidogrel monotherapy (Sun, Li, Li, Zhang, Zhu, Liu et al., 2015; Tornio, Flynn, Morant, Velten, Palmer, MacDonald et al., 2018). On the other hand, the increased function CYP2C19*17 allele has been associated with increased risk of bleeding in some studies (Sibbing, Koch, Gebhard, Schuster, Braun, Stegherr et al., 2010). Based on the current available evidence, alternative antiplatelet therapy is recommended for CYP2C19 IMs and PMs in the CPIC guideline (Scott et al., 2013).

There is also strong evidence on the influence of CYP2C19 genotype on TCAs and SSRIs that are metabolized by CYP2C19 (Hicks, Sangkuhl, Swen, Ellingrod, Muller, Shimoda et al., 2016). Tertiary amine TCAs, namely amitriptyline, clomipramine, doxepin, imipramine, and trimipramine, are demethylated by CYPC19 to corresponding pharmacologically active secondary amines (e.g., amitriptyline to nortriptyline), and both the tertiary amines and secondary amines are metabolized by CYP2D6 to less active hydroxy-metabolites. Tertiary amines have a stronger serotonergic effect, whereas secondary amines have a more pronounced noradrenergic effect, and thus changes in CYP2C19 activity can have an impact on clinical response or adverse effects of tertiary amines (Gillman, 2007). Both CYP2C19 poor and ultrarapid/rapid metabolizers are at risk of suboptimal response to tertiary amines, and other TCAs not metabolized by CYP2C19 are 
recommended for these individuals in the CPIC guideline (Hicks et al., 2016). Furthermore, the SSRIs citalopram, escitalopram, and sertraline are metabolized by CYP2C19, and especially for citalopram and escitalopram, CYP2C19 UMs are at risk of therapeutic failure and PMs at increased risk of side effects if normal recommended doses are used (Hicks, Bishop, Sangkuhl, Müller, Ji, Leckband et al., 2015; Jukic, Haslemo, Molden, \& Ingelman-Sundberg, 2018).

Most PPIs are metabolized by CYP2C19 and their pharmacokinetics are affected by CYP2C19 phenotype (Furuta, Ohashi, Kamata, Takashima, Kosuge, Kawasaki et al., 1998). Both CYP2C19 IMs and PMs have higher PPI plasma concentrations compared to NMs, and consequently, the success rate of H. Pylori eradication therapy depends on CYP2C19 genotype (Zhao, Wang, Yang, Wang, Shi, Xu et al., 2008). In contrast, CYP2C19 UMs are at risk of treatment failure, and consequently dose escalation is recommended for esomeprazole, lansoprazole, omeprazole and pantoprazole in H. Pylori eradication in the UM patients according to the DPWG guideline (Swen, Nijenhuis, de Boer, Grandia, Maitland-van der Zee, Mulder et al., 2011). Also the triazole antifungal voriconazole is metabolized by $\mathrm{CYP} 2 \mathrm{C} 19$, and choosing an alternative antifungal agent not metabolized by CYP2C19 is recommended for both rapid/ultrarapid metabolizers and poor metabolizers due to risk of subtherapeutic concentrations and risk of adverse effects, respectively (Moriyama, Obeng, Barbarino, Penzak, Henning, Scott et al., 2016).

\section{CYP2D6}

Although the protein abundancy of CYP2D6 in the liver is only about 5\% of the total hepatic CYP amount (Y. Zhou et al., 2017), CYP2D6 contributes significantly to the metabolism of roughly 25\% of all drugs in clinical use (He, Chen, Zhou, \& Zhou, 2015). CYP2D6 substrates include TCAs, SSRIs (paroxetine, fluoxetine, fluvoxamine), other psychiatric drugs (venlafaxine, aripiprazole, risperidone), atomoxetine, opioids (codeine, tramadol, oxycodone), antiemetics (ondansetron, 
tropisetron), primaquine, tamoxifen, and cardiovascular drugs (metoprolol, timolol, propafenone). CYP2D6 is inhibited strongly by various drugs, including fluoxetine, paroxetine, terbinafine and moclobemide. Moreover, although it has been thought that CYP2D6 is not inducible, accumulating data indicate that transcriptional regulation of CYP2D6 may account for part of CYP2D6 variability (X. Pan, Ning, \& Jeong, 2017).

The CYP2D6 gene is located on Chr22q13.1 in close proximity to the nonfunctional pseudogenes, $C Y P 2 D 7$ and $C Y P 2 D 8$. There are more than 100 variants with a designated star allele in the highly polymorphic CYP2D6 locus, including CNVs (https://www.pharmvar.org/gene/CYP2D6, accessed 31 Jan 2018). Overall, the different variations confer no, decreased, normal, or increased function, leading to huge variability in enzyme activity between individuals and populations, ranging from PMs (individuals with two nonfunctional alleles) to UMs (usually carriers of more than two functional CYP2D6 alleles due to gene duplication) (Table 3). The CYP2D6 diplotypes can be translated into predicted more definitive phenotypes using the activity score (AS) system (Gaedigk, Sangkuhl, Whirl-Carrillo, Klein, \& Leeder, 2017; Gaedigk, Simon, Pearce, Bradford, Kennedy, \& Leeder, 2008). To calculate the activity score, alleles are grouped according to their functionality, and a value is assigned to each allele to calculate the AS of each diplotype: no-function (0) alleles $(* 3, * 4, * 4 x N, * 5, * 6, * 7, * 8, * 11, * 12, * 36, * 40, * 42, * 56)$, decreased-function $(0.5)$ alleles $(* 9, * 10, * 17, * 29, * 41, * 44, * 49)$, normal-function (1) alleles $(* 2$, $* 35, * 43, * 45)$, and increased-function (2) alleles $(* 1 x N, * 2 x N)$. Accordingly, the CYP2D6 phenotype can thus be inferred as poor (AS 0), intermediate (0.5), normal (1-2) or ultrarapid ( $>2)$ metabolizer. There is lack of consensus concerning whether patients with an AS of 1.0 should be assigned a normal or intermediate phenotype, and in some reports, they have been classified as normal-slow metabolizers, and individuals with an AS of 1.5-2 as normal-fast metabolizers (Gaedigk, Sangkuhl, et al., 2017; Gaedigk et al., 2008). 
$C Y P 2 D 6$ allele frequencies vary substantially between populations. The $C Y P 2 D 6 * 2$ allele, conferring normal CYP2D6 function, and the variant defining CYP2D6*4 (rs3892097), causing a splicing defect and an inactive CYP2D6 gene product, are frequent in European, African, South Asian, and admixed American populations, with allele frequencies of $27-36 \%$ and $12-16 \%$, respectively (Y. Zhou et al., 2017). On the other hand, the inactive alleles CYP2D6*3 (4\%) and $C Y P 2 D 6 * 6(2 \%)$ are only found in individuals of European ancestry, while the decreased function allele $C Y P 2 D 6^{*} 10$ is almost exclusively found in African, South Asian, and particularly in East Asian populations, where it is the most common $C Y P 2 D 6$ allele $(59 \%)$. CYP2D6*14 is only found in East Asian populations (2\%), while CYP2D6*17 (20\%), CYP2D6*29 (9\%), and CYP2D6*43 (2\%) are African haplotypes. The duplicated increased-function alleles $C Y P 2 D 6^{*} 1 x N$ and $C Y P 2 D 6^{*} 2 x N$ occur with frequencies of $1-2 \%$ in whites and Asians but are much more common in certain African populations, in which their frequency can be up to $29 \%$, and can be enriched in some smaller populations, such as the Finns (7\%) (Pietarinen, Tornio, \& Niemi, 2016). The frequencies of deletions (CYP2D6*5) vary from $1 \%$ to $7 \%$ (Gaedigk, Sangkuhl, et al., 2017).

Codeine is a weak opioid analgesic, whose opioid effect is dependent on morphine formed by CYP2D6 (Crews, Gaedigk, Dunnenberger, Leeder, Klein, Caudle et al., 2014). Accordingly, the rate of bioactivation and analgesic efficacy of codeine are markedly decreased in CYP2D6 PMs and increased in UMs, even though clinical evidence from pain studies regarding the effect of CYP2D6 genotype is still lacking (Somogyi, Coller, \& Barratt, 2015). There are several case reports of severe or life-threatening adverse effects following standard codeine doses in CYP2D6 UMs. Consequently, the CPIC guideline recommends using alternative analgesics in PMs and UMs, and codeine is contraindicated by the medicines agencies in known CYP2D6 UMs. In addition to codeine, also other opioids, including tramadol, hydrocodone and oxycodone, are O-demethylated by CYP2D6. As O-desmethyltramadol is mainly responsible for the opioid effects of tramadol, similarly to codein, CYP2D6 PMs and UMs can be susceptible to treatment failure when tramadol is used 
(Orliaguet, Hamza, Couloigner, Denoyelle, Loriot, Broly et al., 2015). However, the effect of genetic variability in CYP2D6 on the analgesic efficacy and risk of toxicity with oxycodone and hydromorphone seems to be smaller due to the variable significance of parent drug and metabolites to the opioid effects.

All TCAs are metabolized to less active hydroxylated metabolites almost exclusively by CYP2D6 (Hicks et al., 2016). Therefore, there is huge CYP2D6 genotype dependent variability in their metabolic clearance. Accordingly, clinical studies have shown particularly for amitriptyline and nortriptyline that standard doses of TCAs can fail to produce sufficient drug concentrations in the systemic circulation in UMs, while the concentrations of TCAs may reach supratherapeutic levels in PMs, resulting in risk of therapeutic failure or intolerable adverse effects, respectively. The CPIC guideline therefore recommends avoiding TCAs in CYP2D6 UMs and PMs.

Of the SSRIs, fluoxetine, and particularly fluvoxamine and paroxetine are metabolized by CYP2D6 (Hicks et al., 2015). CYP2D6 UMs have been shown to be at risk of low or undetectable plasma paroxetine concentrations, which may be associated with an increased likelihood of therapeutic failure. Therefore, it is advisable to select an alternative antidepressant in UMs. CYP2D6 PMs, on the other hand have greater drug exposure to fluvoxamine and paroxetine, compared to NMs, and therefore it is recommended that their doses should be reduced by $30-50 \%$ in PMs, if alternative antidepressants cannot be selected. Fluoxetine itself is pharmacologically active, and it is converted to a major active metabolite, R-norfluoxetine by CYP2D6. Therefore, CYP2D6 PMs have high fluoxetine levels and low norfluoxetine levels, and their total sum may not vary to a clinically significant degree between CYP2D6 genotypes.

The 5-hydroxytryptamine receptor antagonists ondansetron and tropisetron, that are used as antiemetics, are metabolized to inactive metabolites to a significant degree by CYP2D6 (Bell, Caudle, Whirl-Carrillo, Gordon, Hikino, Prows et al., 2017). Based on some pharmacokinetic data, the metabolism and clearance of tropisetron is highly dependent on CYP2D6 phenotype, while the effect 
on ondansetron pharmacokinetics is only moderate. More importantly, there is clinical evidence showing that CYP2D6 UMs are at risk of reduced antiemetic response to ondansetron and tropisetron. Accordingly, the CPIC guideline gives a moderate recommendation to select an alternative antiemetic approach in CYP2D6 UMs.

Tamoxifen is an antiestrogenic agent that is used in treatment of breast cancer. It is bioactivated to 4-hydroxytamoxifen and endoxifen by CYP2D6 (Goetz, Sangkuhl, Guchelaar, Schwab, Province, Whirl-Carrillo et al., 2018). Compared to NMs, CYP2D6 PMs exhibit lower endoxifen concentrations and a higher risk of cancer recurrence when tamoxifen is used as an adjuvant in early breast cancer. The CPIC guideline for tamoxifen therefore recommends the use of alternative hormonal therapy for CYP2D6 poor metabolizers. For CYP2D6 IMs and NMs with an AS of 1 , the recommendation is to consider alternative hormonal therapy, or if aromatase inhibitor use is contraindicated, to consider a higher but approved tamoxifen dose. For PMs, higher dose tamoxifen (40 mg/day) can be considered if there are contraindications to aromatase inhibitor therapy.

\section{CYP3A subfamily}

The CYP3A subfamily consists of four genes, namely $C Y P 3 A 4, C Y P 3 A 5, C Y P 3 A 7, C Y P 3 A 43$ located on chromosome 7q22.1. CYP3A4 and CYP3A5 are abundantly expressed in the adult liver (Zhang et al., 2016). The expression of the other two isoforms is much lower, but CYP3A7 is abundantly expressed in fetal liver, contributing to about $50 \%$ of the total microsomal CYP protein content. CYP3A4 is important for the metabolism of about $50 \%$ of clinically used drugs including wide range of drugs and drug classes: benzodiazepines, calcium channel blockers, cyclosporine, macrolide antibiotics, opioids, several statins, and it also contributes to the metabolism of steroid hormones (S. F. Zhou, 2008). CYP3A4 is inhibited by a wide range of xenobiotics, such as erythromycin, grapefruit juice, ketoconazole, and HIV protease inhibitors. CYP3A4 is also highly inducible by PXR and CAR ligands. CYP3A5 is highly similar to CYP3A4, resulting in highly overlapping substrate selectivity. 


\subsection{CYP3A4}

CYP3A4 activity is highly variable, but genetic variants in the CYP3A4 gene have explained only a minor portion of this variability (Werk \& Cascorbi, 2014). So far, the most relevant $C Y P 3 A 4$ variant to explain CYP3A4 activity appears to be the intronic $C Y P 3 A 4 * 22($ rs35599367 C $>$ T) variant, which occurs with a MAF of 5\% in Europeans, and about 3\% in admixed Americans, but is rare in many other populations (Y. Zhou et al., 2017). In 2011 it was shown to be associated with reduced CYP3A4 mRNA expression in liver samples, and with lower statin dose requirement for lipid control (D. Wang, Guo, Wrighton, Cooke, \& Sadee, 2011). These findings have been subsequently replicated in several studies (Werk \& Cascorbi, 2014). On the other hand, another widely studied variant, CYP $3 A 4 * 1 B$, appears to have no or very limited functional impact on CYP3A4 (García-Martín, Martínez, Pizarro, Garcia-Gamito, Gullsten, Raunio et al., 2002), in contrast to some initial reports which may have been influenced by its linkage disequilibrium with $C Y P 3 A 5^{*} 1$. In addition to several non-synonymous exonic variants, two total loss-of-function variants have been described (CYP3A4*20 and *26), both initially discovered based on single individuals with abnormal pharmacokinetics (Werk, Lefeldt, Bruckmueller, Hemmrich-Stanisak, Franke, Roos et al., 2014; Westlind-Johnsson, Hermann, Huennemeyer, Hauns, Lahu, Nassr et al., 2006). The frequency of these alleles is generally very low, but for example $C Y P 3 A 4^{*} 20$ is present in the Spanish population with an allele frequency of $1.2 \%$ (Apellaniz-Ruiz, Inglada-Perez, Naranjo, Sanchez, Mancikova, Curras-Freixes et al., 2015).

The association of $C Y P 3 A 4 * 22$ with reduced metabolic activity for several CYP3A4 substrates such as cyclosporine, erythromycin, sunitinib, tamoxifen, and quetiapine is well established (Werk \& Cascorbi, 2014). Few studies have reported effects on pharmacodynamic endpoints for e.g., fluticasone in asthma and CYP3A4-metabolized statins in lipid control. However, no genotype-based dosing guidelines have been published for CYP3A4. 


\subsection{CYP3A5}

CYP3A5 substrate selectivity overlaps with that of CYP3A4, and CYP3A5 contributes significantly to the CYP3A metabolic activity in individuals who express fully functional CYP3A5, i.e., in carriers of at least one $C Y P 3 A 5^{*} 1$ allele (Kuehl, Zhang, Lin, Lamba, Assem, Schuetz et al., 2001). The most common and well-studied non-functional variant allele is the CYP3A5*3 (Lamba, Hebert, Schuetz, Klein, \& Altman, 2012). This allele is very common in admixed Americans, Europeans, East Asians, and South Asians, constituting the major allele with a frequency of $80 \%, 94 \%, 71 \%$, and $67 \%$, respectively (Y. Zhou et al., 2017). The allele frequency has been reported to correlate with the distance from the equator (Thompson, Kuttab-Boulos, Witonsky, Yang, Roe, \& Di Rienzo, 2004), and it is considerably rarer in Africans (allele frequency 17\%) than in other superpopulations. Other nonfunctional alleles are generally rare, but $C Y P 3 A 5^{*} 6$ and $* 7$ occur in African populations with allele frequencies of $15 \%$ and $10 \%$ (Y. Zhou et al., 2017).

The strongest evidence for clinical implications of CYP3A5 variation is available for tacrolimus, which is one of the most widely used immunosuppressive medications in solid organ transplantation. Blood concentrations of tacrolimus have been associated with CYP3A5 genotype in numerous studies, and CYP3A5 expressers have a higher tacrolimus clearance than non-expressers (Birdwell, Decker, Barbarino, Peterson, Stein, Sadee et al., 2015). Therapeutic drug monitoring is employed with tacrolimus therapy, and studies have shown that CYP3A5 genotyping is helpful for achieving target trough whole blood concentrations when treatment is initiated. Less evidence is available on its effect on clinical outcomes. Furthermore, in liver transplant patients, both the genotype of the recipient and that of the donor liver can influence tacrolimus clearance, since CYP3A5 is expressed in both the intestine and the liver. However, the evidence is inconclusive at the moment regarding the relative significance of donor's and recipient's genotypes in liver transplants where the genotype is different between the two. 
The evidence regarding CYP3A5 genotype and statins metabolized by CYP3A enzymes is somewhat controversial, as some studies have shown poorer LDL-response to statin therapy in CYP3A5 expressors than in non-expressors (Kivistö, Niemi, Schaeffeler, Pitkälä, Tilvis, Fromm et al., 2004), whereas other studies have implicated reduced response in CYP3A5 non-expressors (Willrich, Hirata, Genvigir, Arazi, Rebecchi, Rodrigues et al., 2008). Furthermore, there is limited evidence that $C Y P 3 A 5 * 3$ is associated with statin-induced myopathy. In one study, atorvastatinassociated myalgia cases with the $C Y P 3 A 5 * 3 / * 3$ genotype had higher creatine kinase levels than those with the $C Y P 3 A 5^{*} 1 / * 3$ genotype (Wilke, Moore, \& Burmester, 2005). In addition, an association with the $C Y P 3 A 5$ genotype and treatment-related toxicity has been reported for the anticancer agents sunitinib and vincristine, which are both metabolized by CYP3A enzymes (Egbelakin, Ferguson, MacGill, Lehmann, Topletz, Quinney et al., 2011; Garcia-Donas, Esteban, Leandro-Garcia, Castellano, del Alba, Climent et al., 2011). However, due to limited evidence, no other genotypebased dosing guidelines than those for tacrolimus have been published for CYP3A5 to date.

\section{Conclusion}

Due to substantial research efforts, there has been a tremendous progress in understanding the genetic variability of drug-metabolizing CYP enzymes, their genotype-phenotype relationships, as well as their clinical significance. During the last decade, important advances have included

- the discovery and characterization of the clinical relevance of certain fairly common functionally relevant CYP alleles (particularly $C Y P 2 C 19 * 17$ and $C Y P 3 A 4 * 22$ ),

- recognition of the significance of CYP alleles common in individuals of non-European ancestry (e.g., certain decreased function $C Y P 2 C 9$ alleles),

- understanding of the significance of rare loss-of-function CYP variants, 
- realization that in all populations, the proportion that possess an "actionable pharmacogene" (i.e., a pharmacogenetic variant which is associated with actionable prescribing decision for a specific drug) is very high,

- detailed characterization of the clinical usefulness of pharmacogenetic approaches related to specific drugs (even prospective, randomized controlled clinical trials of pharmacogenetics versus conventional approaches have been conducted with warfarin),

- and perhaps most importantly the systematic production of drug specific evidence-based pharmacogenetic guidelines.

At the same time with increased understanding of the pharmacogenetics of CYP enzymes, there has been a rapid movement from traditional genotyping towards an era of large-scale exome and genome sequencing. This has already now increased the number of reported rare non-synonymous CYP variants to thousands (Fujikura, Ingelman-Sundberg, \& Lauschke, 2015). Such variants of uncertain significance will pose a special challenge to pharmacogenetics, since they may have a very large impact on drug pharmacokinetics when they are present as a diplotype together with a common loss-of-function variant. Improvement of various computational approaches and large-scale functional assays will be needed to make significant progress in understanding the significance of such a multitude of rare variants, since there will be no possibility to investigate each of them clinically.

Despite all the scientific advances, the incorporation of pharmacogenetic information to clinical routine has been slow. So far, only few hospitals worldwide have adapted large-scale preemptive genotyping in clinical use. The reasons for the slow progress include organizational, ethical, legal and financial issues, in addition to medical issues. Sometimes, a main reason has been that alternative drugs with a perceived or known more reliable clinical effect have become preferred, in order to avoid pharmacogenetic complexities (Azmoon \& Angiolillo, 2013). 
In the future, the discovery and characterization of pharmacogenes and their variants will continue at a considerable rate, and work will be continued to compose and update pharmacogenetics consensus guidelines. In addition, research efforts will be needed to characterize the clinical utility and practicality of CYP genotyping in properly designed clinical trials. Moreover, incorporation of the pharmacogenetics guidelines to health care routines will require development of computational approaches, as well as electronic medical records and their interfaces, so that the use of pharmacogenetics information to support medical decisions is smooth and effective; a key challenge will be the provision of clear, unambiguous guidance to health care providers. At the same time, it should be kept in mind that in addition to genetic variability, CYP phenotypes are altered by multiple other individual factors, such as disease states and drug interactions.

\section{Conflict of interest}

The authors declare no conflict of interest. 
Table 1. Drug metabolizing CYP enzymes, their chromosomal location, clinical significance of their genetic variability and examples of substrates. Substrates with an associated Clinical Pharmacogenetics Implementation (CPIC) guideline are given in bold.

\begin{tabular}{|c|c|c|c|}
\hline $\begin{array}{l}\text { Enzyme / } \\
\text { gene }\end{array}$ & $\begin{array}{l}\text { Chromo- } \\
\text { some }\end{array}$ & $\begin{array}{l}\text { Significance of } \\
\text { genetic } \\
\text { variability }\end{array}$ & Examples of substrates \\
\hline CYP1A2 & $15 q 24.1$ & $+/-$ & $\begin{array}{l}\text { Agomelatine, caffeine, clozapine, lidocaine, } \\
\text { melatonin, tacrine, theophylline, tizanidine }\end{array}$ \\
\hline CYP2A6 & $19 q 13.2$ & + & Cotinine, coumarin, letrozole, nicotine, tegafur \\
\hline CYP2B6 & $19 q 13.2$ & + & Bupropion, efavirenz, cyclophosphamide \\
\hline CYP2C8 & $10 \mathrm{q} 23.33$ & + & $\begin{array}{l}\text { Amodiaquine, cerivastatin, dasabuvir, imatinib, } \\
\text { loperamide, montelukast, pioglitazone, paclitaxel, } \\
\text { repaglinide, rosiglitazone }\end{array}$ \\
\hline CYP2C9 & $10 \mathrm{q} 23.33$ & ++ & $\begin{array}{l}\text { Acenocoumarol, diclofenac, fluvastatin, glimiepiride, } \\
\text { glipizide, ibuprofen, losartan, phenytoin, S-warfarin }\end{array}$ \\
\hline CYP2C19 & $10 \mathrm{q} 23.33$ & ++ & $\begin{array}{l}\text { Amitriptyline (and other tertiary amine tricyclic } \\
\text { antidepressants), clopidogrel, (es)citalopram, } \\
\text { omeprazole, pantoprazole, sertraline, voriconazole }\end{array}$ \\
\hline CYP2D6 & $22 q 13.2$ & ++ & $\begin{array}{l}\text { Amitriptyline (and other tricyclic } \\
\text { antidepressants), aripiprazole, atomoxetine, } \\
\text { codeine, dextromethorphan, fluvoxamine, } \\
\text { metoprolol, mianserine, MDMA, ondansetron, } \\
\text { paroxetine, propafenone, risperidone, tamoxifen, } \\
\text { thioridazine, timolol, tropisetron, venlafaxine }\end{array}$ \\
\hline
\end{tabular}




\begin{tabular}{|c|c|c|c|}
\hline CYP2E1 & $10 \mathrm{q} 26.3$ & $+/-$ & Ethanol, halothane, paracetamol \\
\hline CYP2J2 & $1 \mathrm{p} 32.1$ & $+/-$ & $\begin{array}{l}\text { Amiodarone, arachidonic acid, astemizole, } \\
\text { cyclosporine }\end{array}$ \\
\hline CYP3A4 & $7 \mathrm{q} 22.1$ & $+/-$ & $\begin{array}{l}\text { Alfentanil, alprazolam, atorvastatin, budesonide, } \\
\text { buspirone, cyclosporine, dexamethasone, } \\
\text { erythromycin, felodipine, gefitinib, lovastatin, } \\
\text { midazolam, nifedipine, quetiapine, saquinavir, } \\
\text { sildenafil, simvastatin, tacrolimus, testosterone, } \\
\text { triazolam, verapamil, vincristine }\end{array}$ \\
\hline CYP3A5 & $7 \mathrm{q} 22.1$ & ++ & $\begin{array}{l}\text { Saquinavir, tacrolimus, verapamil, substrates } \\
\text { overlap with CYP3A4 }\end{array}$ \\
\hline
\end{tabular}

+/- Minor or no clinical significance

+ Moderate clinical significance

++ Major clinical significance 
Table 2. Assignment of likely phenotypes based on examples of common diplotypes. Phenotype classification is based on consensus terms from the Clinical Pharmacogenetics Implementation Consortium (CPIC) (Caudle et al., 2017).

\section{Examples of diplotypes}

\begin{tabular}{|c|c|c|c|c|}
\hline Phenotype & CYP2C9 & CYP2C19 & CYP2D6 & CYP3A5 \\
\hline Ultrarapid & - & $* 17 / * 17, * 1 / * 17$ & $(* 1 / * 1) \mathrm{xN}^{\mathrm{a}}$, & - \\
\hline or rapid & & & $(* 1 / * 2) \times \mathrm{N}$, & \\
\hline metabolizer & & & $(* 2 / * 2) \times \mathrm{N}$ & \\
\hline Normal & $* 1 / * 1$ & $* 1 / * 1$ & $* 1 / * 1, * 1 / * 2$ & $* 1 / * 1$ \\
\hline \multirow[t]{3}{*}{ metabolizer } & & & $* 2 / * 2, * 1 / * 9$ & \\
\hline & & & $* 1 / * 41, * 41 / * 41$, & \\
\hline & & & $* 1 / * 5, * 1 / * 4$ & \\
\hline Intermediate & $* 1 / * 2, * 1 / * 3$ & $* 1 / * 2, * 1 / * 3$ & $* 4 / * 41, * 5 / * 9$ & $* 1 / * 3$ \\
\hline metabolizer & & $* 2 / * 17^{b}$ & $* 4 / * 10$ & \\
\hline Poor & $* 2 / * 2, * 2 / * 3$, & $* 2 / * 2, * 2 / * 3$ & $* 4 / * 4$ & $* 3 / * 3$ \\
\hline \multirow[t]{3}{*}{ metabolizer } & $* 3 / * 3$ & $* 3 / * 3$ & $(* 4 / * 4) \times \mathrm{xN}$ & \\
\hline & & & $* 3 / * 4, * 5 / * 5$ & \\
\hline & & & $* 5 / * 6$ & \\
\hline
\end{tabular}

${ }^{\mathrm{a}} \mathrm{xN}$ represents the number of CYP2D6 gene copies.

${ }^{\mathrm{b}}$ provisional classification. 
Table 3. Population frequencies of $\mathrm{CYP} 2 \mathrm{C} 9, \mathrm{CYP} 2 \mathrm{C} 19$, and $\mathrm{CYP} 2 \mathrm{D} 6$ phenotypes in major populations.

\begin{tabular}{lccccc}
\hline & $\begin{array}{c}\text { Poor } \\
\text { metabolizer }\end{array}$ & Intermediate & Normal & Ultrarapid & Unknown / \\
& & & & \\
& & & & \\
CYP2C9 & $1.8 \%$ & $23 \%$ & $75 \%$ & - & - \\
Africans & $4.0 \%$ & $32 \%$ & $64 \%$ & - & - \\
Europeans & $0.1 \%$ & $6.6 \%$ & $93 \%$ & - & - \\
East Asians & $4.5 \%$ & $33 \%$ & $62 \%$ & - & - \\
South Asians & $1.2 \%$ & $20 \%$ & $79 \%$ & - & - \\
Americans & & & & & - \\
\hline
\end{tabular}

\section{CYPC19}

$\begin{array}{lccccc}\text { Africans } & 4.8 \% & 24 \% & 17 \% & 16 \% & 38 \% \\ \text { Europeans } & 2.5 \% & 27 \% & 39 \% & 32 \% & 0.0 \% \\ \text { East Asians } & 14 \% & 47 \% & 37 \% & 1.7 \% & 0.2 \% \\ \text { South Asians } & 12 \% & 46 \% & 23 \% & 19 \% & 0.0 \% \\ \text { Americans } & 2.3 \% & 26 \% & 47 \% & 24 \% & 0.0 \%\end{array}$

\section{CYP2D6}

$\begin{array}{lccccc}\text { Africans } & 1.9 \% & 13 \% & 72 \% & 4.5 \% & 9.2 \% \\ \text { Europeans } & 6.1 \% & 7.2 \% & 75 \% & 3.3 \% & 8.5 \% \\ \text { East Asians } & 0.9 \% & 8.7 \% & 86 \% & 1.2 \% & 3.7 \% \\ \text { South Asians } & 1.3 \% & 6.3 \% & 89 \% & 2.8 \% & 0.4 \% \\ \text { Americans } & 3.7 \% & 4.5 \% & 81 \% & 4.8 \% & 5.8 \%\end{array}$

$\bar{a}$ For CYP2C19, rapid $\left.\left(C Y P 2 C 19^{*} 1\right)^{*} 17\right)$ and ultrarapid $\left(C Y P 2 C 19^{*} 17{ }^{*} 17\right)$ metabolizers are combined. 
${ }^{\mathrm{b}}$ For CYP2C9, phenotypes are based on genotyping for defining SNVs of the decreased function alleles $C Y P 2 C 9 * 2, * 3, * 5, * 6, * 8$, and $* 11$, and all alleles that are negative for these SNVs are defaulted to $C Y P 2 C 9^{*} 1$. For CYP2C19 and CYP2D6, alleles whose functional status is indeterminate are included in the calculations.

Based on phenotype frequencies provided by PharmGKB and CPIC in Gene-specific Information Tables (https://www.pharmgkb.org/page/cyp2c9RefMaterials, https://www.pharmgkb.org/page/cyp2c19RefMaterials, https://www.pharmgkb.org/page/cyp2d6RefMaterials; accessed 6 February 2018) 


\section{References}

Al Koudsi, N., \& Tyndale, R. F. (2010). Hepatic CYP2B6 is altered by genetic, physiologic, and environmental factors but plays little role in nicotine metabolism. Xenobiotica, 40(6), 381392. doi: 10.3109/00498251003713958

Amin, N., Byrne, E., Johnson, J., Chenevix-Trench, G., Walter, S., Nolte, I. M., . . van Duijn, C. M. (2012). Genome-wide association analysis of coffee drinking suggests association with CYP1A1/CYP1A2 and NRCAM. Mol Psychiatry, 17(11), 1116-1129. doi: 10.1038/mp.2011.101

Anderson, J. L., Horne, B. D., Stevens, S. M., Woller, S. C., Samuelson, K. M., Mansfield, J. W., . . . Carlquist, J. F. (2012). A randomized and clinical effectiveness trial comparing two pharmacogenetic algorithms and standard care for individualizing warfarin dosing (CoumaGen-II). Circulation, 125(16), 1997-2005. doi: 10.1161/CIRCULATIONAHA.111.070920

Apellaniz-Ruiz, M., Inglada-Perez, L., Naranjo, M. E., Sanchez, L., Mancikova, V., Curras-Freixes, M., . . Rodriguez-Antona, C. (2015). High frequency and founder effect of the CYP3A4*20 loss-of-function allele in the Spanish population classifies CYP3A4 as a polymorphic enzyme. Pharmacogenomics J, 15(3), 288-292. doi: 10.1038/tpj.2014.67

Azmoon, S., \& Angiolillo, D. J. (2013). Switching antiplatelet regimens: alternatives to clopidogrel in patients with acute coronary syndrome undergoing PCI: a review of the literature and practical considerations for the interventional cardiologist. Catheter Cardiovasc Interv, 81(2), 232-242. doi: $10.1002 / \mathrm{ccd} .24480$

Backman, J. T., Filppula, A. M., Niemi, M., \& Neuvonen, P. J. (2016). Role of Cytochrome P450 2C8 in Drug Metabolism and Interactions. Pharmacol Rev, 68(1), 168-241. doi: 68/1/168 [pii]

10.1124/pr.115.011411

Baker, W. L., \& Johnson, S. G. (2016). Pharmacogenetics and oral antithrombotic drugs. Curr Opin Pharmacol, 27, 38-42. doi: 10.1016/j.coph.2016.01.008

Bank, P. C., Caudle, K. E., Swen, J. J., Gammal, R. S., Whirl-Carrillo, M., Klein, T. E., ... Guchelaar, H. J. (2017). Comparison of the Guidelines of the Clinical Pharmacogenetics Implementation Consortium and the Dutch Pharmacogenetics Working Group. Clin Pharmacol Ther. doi: 10.1002/cpt.762

Barratt, D. T., Cox, H. K., Menelaou, A., Yeung, D. T., White, D. L., Hughes, T. P., \& Somogyi, A. A. (2017). CYP2C8 Genotype Significantly Alters Imatinib Metabolism in Chronic Myeloid Leukaemia Patients. Clin Pharmacokinet, 56(8), 977-985. doi: 10.1007/s40262-016-0494-0

Bell, G. C., Caudle, K. E., Whirl-Carrillo, M., Gordon, R. J., Hikino, K., Prows, C. A., . . Schwab, M. (2017). Clinical Pharmacogenetics Implementation Consortium (CPIC) guideline for CYP2D6 genotype and use of ondansetron and tropisetron. Clin Pharmacol Ther, 102(2), 213-218. doi: 10.1002/cpt.598

Bergmann, T. K., Brasch-Andersen, C., Green, H., Mirza, M., Pedersen, R. S., Nielsen, F., ... Brosen, K. (2011). Impact of CYP2C $8 * 3$ on paclitaxel clearance: a population pharmacokinetic and pharmacogenomic study in 93 patients with ovarian cancer. Pharmacogenomics J, 11(2), 113120. doi: 10.1038/tpj.2010.19

Birdwell, K. A., Decker, B., Barbarino, J. M., Peterson, J. F., Stein, C. M., Sadee, W., . . MacPhee, I. A. (2015). Clinical Pharmacogenetics Implementation Consortium (CPIC) Guidelines for CYP3A5 Genotype and Tacrolimus Dosing. Clin Pharmacol Ther, 98(1), 19-24. doi: $10.1002 /$ cpt. 113

Bloom, J., Hinrichs, A. L., Wang, J. C., von Weymarn, L. B., Kharasch, E. D., Bierut, L. J., . . . Murphy, S. E. (2011). The contribution of common CYP2A6 alleles to variation in nicotine metabolism among European-Americans. Pharmacogenet Genomics, 21(7), 403-416. doi: 10.1097/FPC.0b013e328346e8c0 
Boora, G. K., Kanwar, R., Kulkarni, A. A., Abyzov, A., Sloan, J., Ruddy, K. J., . . Beutler, A. S. (2016). Testing of candidate single nucleotide variants associated with paclitaxel neuropathy in the trial NCCTG N08C1 (Alliance). Cancer Med, 5(4), 631-639. doi: 10.1002/cam4.625

Caudle, K. E., Dunnenberger, H. M., Freimuth, R. R., Peterson, J. F., Burlison, J. D., Whirl-Carrillo, M., .. . Hoffman, J. M. (2017). Standardizing terms for clinical pharmacogenetic test results: consensus terms from the Clinical Pharmacogenetics Implementation Consortium (CPIC). Genet Med, 19(2), 215-223. doi: 10.1038/gim.2016.87

Caudle, K. E., Rettie, A. E., Whirl-Carrillo, M., Smith, L. H., Mintzer, S., Lee, M. T., . . Clinical Pharmacogenetics Implementation, C. (2014). Clinical pharmacogenetics implementation consortium guidelines for CYP2C9 and HLA-B genotypes and phenytoin dosing. Clin Pharmacol Ther, 96(5), 542-548. doi: 10.1038/clpt.2014.159

Chen, Y., \& Goldstein, J. A. (2009). The transcriptional regulation of the human CYP2C genes. Curr Drug Metab, 10(6), 567-578.

Chenoweth, M. J., \& Tyndale, R. F. (2017). Pharmacogenetic Optimization of Smoking Cessation Treatment. Trends Pharmacol Sci, 38(1), 55-66. doi: 10.1016/j.tips.2016.09.006

Coffee and Caffeine Genetics Consortium, Cornelis, M. C., Byrne, E. M., Esko, T., Nalls, M. A., Ganna, A., . . Chasman, D. I. (2015). Genome-wide meta-analysis identifies six novel loci associated with habitual coffee consumption. Mol Psychiatry, 20(5), 647-656. doi: 10.1038/mp.2014.107

Cornelis, M. C., Monda, K. L., Yu, K., Paynter, N., Azzato, E. M., Bennett, S. N., . . Caporaso, N. E. (2011). Genome-wide meta-analysis identifies regions on 7p21 (AHR) and 15q24 (CYP1A2) as determinants of habitual caffeine consumption. PLoS Genet, 7(4), e1002033. doi: 10.1371/journal.pgen.1002033

Crews, K. R., Gaedigk, A., Dunnenberger, H. M., Leeder, J. S., Klein, T. E., Caudle, K. E., . . . Clinical Pharmacogenetics Implementation, C. (2014). Clinical Pharmacogenetics Implementation Consortium guidelines for cytochrome P450 2D6 genotype and codeine therapy: 2014 update. Clin Pharmacol Ther, 95(4), 376-382. doi: 10.1038/clpt.2013.254

Daly, A. K., Rettie, A. E., Fowler, D. M., \& Miners, J. O. (2017). Pharmacogenomics of CYP2C9: Functional and Clinical Considerations. J Pers Med, 8(1). doi: 10.3390/jpm8010001

Dawed, A. Y., Donnelly, L., Tavendale, R., Carr, F., Leese, G., Palmer, C. N., . . Zhou, K. (2016). CYP2C8 and SLCO1B1 Variants and Therapeutic Response to Thiazolidinediones in Patients With Type 2 Diabetes. Diabetes Care, 39(11), 1902-1908. doi: 10.2337/dc15-2464

Desta, Z., Kreutz, Y., Nguyen, A. T., Li, L., Skaar, T., Kamdem, L. K., . . Flockhart, D. A. (2011). Plasma letrozole concentrations in postmenopausal women with breast cancer are associated with CYP2A6 genetic variants, body mass index, and age. Clin Pharmacol Ther, 90(5), 693700. doi: $10.1038 /$ clpt.2011.174

Di, Y. M., Chow, V. D., Yang, L. P., \& Zhou, S. F. (2009). Structure, function, regulation and polymorphism of human cytochrome P450 2A6. Curr Drug Metab, 10(7), 754-780.

Ding, X., \& Kaminsky, L. S. (2003). Human extrahepatic cytochromes P450: function in xenobiotic metabolism and tissue-selective chemical toxicity in the respiratory and gastrointestinal tracts. Annu Rev Pharmacol Toxicol, 43, 149-173. doi: 10.1146/annurev.pharmtox.43.100901.140251

Egbelakin, A., Ferguson, M. J., MacGill, E. A., Lehmann, A. S., Topletz, A. R., Quinney, S. K., . . . Renbarger, J. L. (2011). Increased risk of vincristine neurotoxicity associated with low CYP3A5 expression genotype in children with acute lymphoblastic leukemia. Pediatr Blood Cancer, 56(3), 361-367. doi: 10.1002/pbc.22845

Figueiras, A., Estany-Gestal, A., Aguirre, C., Ruiz, B., Vidal, X., Carvajal, A., . . group, E. (2016). CYP2C9 variants as a risk modifier of NSAID-related gastrointestinal bleeding: a casecontrol study. Pharmacogenet Genomics, 26(2), 66-73. doi: 10.1097/FPC.0000000000000186 
Fuhr, U., Rost, K. L., Engelhardt, R., Sachs, M., Liermann, D., Belloc, C., . . Staib, A. H. (1996). Evaluation of caffeine as a test drug for CYP1A2, NAT2 and CYP2E1 phenotyping in man by in vivo versus in vitro correlations. Pharmacogenetics, 6(2), 159-176.

Fujikura, K., Ingelman-Sundberg, M., \& Lauschke, V. M. (2015). Genetic variation in the human cytochrome P450 supergene family. Pharmacogenet Genomics, 25(12), 584-594. doi: 10.1097/FPC.0000000000000172

Fukami, T., Nakajima, M., Higashi, E., Yamanaka, H., Sakai, H., McLeod, H. L., \& Yokoi, T. (2005). Characterization of novel CYP2A6 polymorphic alleles (CYP2A6*18 and CYP2A6*19) that affect enzymatic activity. Drug Metab Dispos, 33(8), 1202-1210. doi: 10.1124/dmd.105.004994

Furuta, T., Ohashi, K., Kamata, T., Takashima, M., Kosuge, K., Kawasaki, T., ... Kaneko, E. (1998). Effect of genetic differences in omeprazole metabolism on cure rates for Helicobacter pylori infection and peptic ulcer. Ann Intern Med, 129(12), 1027-1030.

Gaedigk, A., Ingelman-Sundberg, M., Miller, N. A., Leeder, J. S., Whirl-Carrillo, M., Klein, T. E., \& PharmVar Steering, C. (2017). The Pharmacogene Variation (PharmVar) Consortium: Incorporation of the Human Cytochrome P450 (CYP) Allele Nomenclature Database. Clin Pharmacol Ther. doi: 10.1002/cpt.910

Gaedigk, A., Sangkuhl, K., Whirl-Carrillo, M., Klein, T., \& Leeder, J. S. (2017). Prediction of CYP2D6 phenotype from genotype across world populations. Genet Med, 19(1), 69-76. doi: 10.1038/gim.2016.80

Gaedigk, A., Simon, S. D., Pearce, R. E., Bradford, L. D., Kennedy, M. J., \& Leeder, J. S. (2008). The CYP2D6 activity score: translating genotype information into a qualitative measure of phenotype. Clin Pharmacol Ther, 83(2), 234-242. doi: 10.1038/sj.clpt.6100406

Gage, B. F., Bass, A. R., Lin, H., Woller, S. C., Stevens, S. M., Al-Hammadi, N., . . Eby, C. S. (2017). Effect of Genotype-Guided Warfarin Dosing on Clinical Events and Anticoagulation Control Among Patients Undergoing Hip or Knee Arthroplasty: The GIFT Randomized Clinical Trial. JAMA, 318(12), 1115-1124. doi: 10.1001/jama.2017.11469

Gage, B. F., Eby, C., Johnson, J. A., Deych, E., Rieder, M. J., Ridker, P. M., . . McLeod, H. L. (2008). Use of pharmacogenetic and clinical factors to predict the therapeutic dose of warfarin. Clin Pharmacol Ther, 84(3), 326-331. doi: 10.1038/clpt.2008.10

Garcia-Donas, J., Esteban, E., Leandro-Garcia, L. J., Castellano, D. E., del Alba, A. G., Climent, M. A., ... Rodríguez-Antona, C. (2011). Single nucleotide polymorphism associations with response and toxic effects in patients with advanced renal-cell carcinoma treated with firstline sunitinib: a multicentre, observational, prospective study. Lancet Oncol, 12(12), 11431150. doi: 10.1016/S1470-2045(11)70266-2

García-Martín, E., Martínez, C., Pizarro, R. M., Garcia-Gamito, F. J., Gullsten, H., Raunio, H., \& Agúndez, J. A. (2002). CYP3A4 variant alleles in white individuals with low CYP3A4 enzyme activity. Clin Pharmacol Ther, 71(3), 196-204. doi: 10.1067/mcp.2002.121371

Gatanaga, H., Hayashida, T., Tsuchiya, K., Yoshino, M., Kuwahara, T., Tsukada, H., ... Oka, S. (2007). Successful efavirenz dose reduction in HIV type 1-infected individuals with cytochrome P450 2B6 *6 and *26. Clin Infect Dis, 45(9), 1230-1237. doi: 10.1086/522175

Gillman, P. K. (2007). Tricyclic antidepressant pharmacology and therapeutic drug interactions updated. Br J Pharmacol, 151(6), 737-748. doi: 10.1038/sj.bjp.0707253

Goetz, M. P., Sangkuhl, K., Guchelaar, H. J., Schwab, M., Province, M., Whirl-Carrillo, M., ... Klein, T. E. (2018). Clinical Pharmacogenetics Implementation Consortium (CPIC) Guideline for CYP2D6 and Tamoxifen Therapy. Clin Pharmacol Ther. doi: 10.1002/cpt. 1007

Gunes, A., \& Dahl, M. L. (2008). Variation in CYP1A2 activity and its clinical implications: influence of environmental factors and genetic polymorphisms. Pharmacogenomics, 9(5), 625-637. doi: 10.2217/14622416.9.5.625 
Haas, D. W., Kwara, A., Richardson, D. M., Baker, P., Papageorgiou, I., Acosta, E. P., . . Court, M. H. (2014). Secondary metabolism pathway polymorphisms and plasma efavirenz concentrations in HIV-infected adults with CYP2B6 slow metabolizer genotypes. $J$ Antimicrob Chemother, 69(8), 2175-2182. doi: 10.1093/jac/dku110

He, Z. X., Chen, X. W., Zhou, Z. W., \& Zhou, S. F. (2015). Impact of physiological, pathological and environmental factors on the expression and activity of human cytochrome P450 2D6 and implications in precision medicine. Drug Metab Rev, 47(4), 470-519. doi: 10.3109/03602532.2015.1101131

Henningsson, A., Marsh, S., Loos, W. J., Karlsson, M. O., Garsa, A., Mross, K., . . McLeod, H. L. (2005). Association of CYP2C8, CYP3A4, CYP3A5, and ABCB1 polymorphisms with the pharmacokinetics of paclitaxel. Clin Cancer Res, 11(22), 8097-8104. doi: 10.1158/10780432.CCR-05-1152

Hicks, J. K., Bishop, J. R., Sangkuhl, K., Müller, D. J., Ji, Y., Leckband, S. G., . . . Clinical Pharmacogenetics Implementation, C. (2015). Clinical Pharmacogenetics Implementation Consortium (CPIC) Guideline for CYP2D6 and CYP2C19 Genotypes and Dosing of Selective Serotonin Reuptake Inhibitors. Clin Pharmacol Ther, 98(2), 127-134. doi: 10.1002/cpt.147

Hicks, J. K., Sangkuhl, K., Swen, J. J., Ellingrod, V. L., Muller, D. J., Shimoda, K., . . Stingl, J. C. (2016). Clinical pharmacogenetics implementation consortium guideline (CPIC) for CYP2D6 and CYP2C19 genotypes and dosing of tricyclic antidepressants: 2016 update. Clin Pharmacol Ther. doi: 10.1002/cpt.597

Hoffman, S. M., Nelson, D. R., \& Keeney, D. S. (2001). Organization, structure and evolution of the CYP2 gene cluster on human chromosome 19. Pharmacogenetics, 11(8), 687-698.

Hukkanen, J., Jacob, P., 3rd, \& Benowitz, N. L. (2005). Metabolism and disposition kinetics of nicotine. Pharmacol Rev, 57(1), 79-115. doi: 10.1124/pr.57.1.3

International Warfarin Pharmacogenetics Consortium, Klein, T. E., Altman, R. B., Eriksson, N., Gage, B. F., Kimmel, S. E., . . . Johnson, J. A. (2009). Estimation of the warfarin dose with clinical and pharmacogenetic data. $N$ Engl $J$ Med, 360(8), 753-764. doi: 10.1056/NEJMoa0809329

Johnson, J. A., Caudle, K. E., Gong, L., Whirl-Carrillo, M., Stein, C. M., Scott, S. A., .. . Wadelius, M. (2017). Clinical Pharmacogenetics Implementation Consortium (CPIC) Guideline for Pharmacogenetics-Guided Warfarin Dosing: 2017 Update. Clin Pharmacol Ther, 102(3), 397-404. doi: 10.1002/cpt.668

Jorgensen, A. L., FitzGerald, R. J., Oyee, J., Pirmohamed, M., \& Williamson, P. R. (2012). Influence of CYP2C9 and VKORC1 on patient response to warfarin: a systematic review and metaanalysis. PLoS One, 7(8), e44064. doi: 10.1371/journal.pone.0044064

Jukic, M. M., Haslemo, T., Molden, E., \& Ingelman-Sundberg, M. (2018). Impact of CYP2C19 Genotype on Escitalopram Exposure and Therapeutic Failure: A Retrospective Study Based on 2,087 Patients. Am J Psychiatry, appiajp201717050550. doi: 10.1176/appi.ajp.2017.17050550

Kaida, Y., Inui, N., Suda, T., Nakamura, H., Watanabe, H., \& Chida, K. (2008). The CYP2A6*4 allele is determinant of S-1 pharmacokinetics in Japanese patients with non-small-cell lung cancer. Clin Pharmacol Ther, 83(4), 589-594. doi: 10.1038/sj.clpt.6100484

Kaspera, R., Naraharisetti, S. B., Tamraz, B., Sahele, T., Cheesman, M. J., Kwok, P. Y., .. . Totah, R. A. (2010). Cerivastatin in vitro metabolism by CYP2C8 variants found in patients experiencing rhabdomyolysis. Pharmacogenet Genomics, 20(10), 619-629. doi: 10.1097/FPC.0b013e32833ecace

Kazui, M., Nishiya, Y., Ishizuka, T., Hagihara, K., Farid, N. A., Okazaki, O., . . Kurihara, A. (2010). Identification of the human cytochrome P450 enzymes involved in the two oxidative steps in the bioactivation of clopidogrel to its pharmacologically active metabolite. Drug Metab Dispos, 38(1), 92-99. doi: 10.1124/dmd.109.029132 
Kimmel, S. E., French, B., Kasner, S. E., Johnson, J. A., Anderson, J. L., Gage, B. F., . . . Investigators, C. (2013). A pharmacogenetic versus a clinical algorithm for warfarin dosing. N Engl J Med, 369(24), 2283-2293. doi: 10.1056/NEJMoa1310669

Kirchheiner, J., \& Brockmöller, J. (2005). Clinical consequences of cytochrome P450 2C9 polymorphisms. Clin Pharmacol Ther, 77(1), 1-16. doi: 10.1016/j.clpt.2004.08.009

Kivistö, K. T., Niemi, M., Schaeffeler, E., Pitkälä, K., Tilvis, R., Fromm, M. F., . . Strandberg, T. (2004). Lipid-lowering response to statins is affected by CYP3A5 polymorphism. Pharmacogenetics, 14(8), 523-525.

Kong, S. Y., Lim, H. S., Nam, B. H., Kook, M. C., Kim, Y. W., Ryu, K. W., . . Park, S. R. (2009). Association of CYP2A6 polymorphisms with S-1 plus docetaxel therapy outcomes in metastatic gastric cancer. Pharmacogenomics, 10(7), 1147-1155. doi: 10.2217/pgs.09.48

Kuehl, P., Zhang, J., Lin, Y., Lamba, J., Assem, M., Schuetz, J., . . Schuetz, E. (2001). Sequence diversity in CYP3A promoters and characterization of the genetic basis of polymorphic CYP3A5 expression. Nat Genet, 27(4), 383-391. doi: 10.1038/86882

Lam, S. W., Frederiks, C. N., van der Straaten, T., Honkoop, A. H., Guchelaar, H. J., \& Boven, E. (2016). Genotypes of CYP2C8 and FGD4 and their association with peripheral neuropathy or early dose reduction in paclitaxel-treated breast cancer patients. Br J Cancer, 115(11), 13351342. doi: $10.1038 /$ bjc. 2016.326

Lamba, J., Hebert, J. M., Schuetz, E. G., Klein, T. E., \& Altman, R. B. (2012). PharmGKB summary: very important pharmacogene information for CYP3A5. Pharmacogenet Genomics, 22(7), 555-558. doi: 10.1097/FPC.0b013e328351d47f

Lee, A. M., Jepson, C., Hoffmann, E., Epstein, L., Hawk, L. W., Lerman, C., \& Tyndale, R. F. (2007). CYP2B6 genotype alters abstinence rates in a bupropion smoking cessation trial. Biol Psychiatry, 62(6), 635-641. doi: 10.1016/j.biopsych.2006.10.005

Läpple, F., von Richter, O., Fromm, M. F., Richter, T., Thon, K. P., Wisser, H., . . Kivistö, K. T. (2003). Differential expression and function of CYP2C isoforms in human intestine and liver. Pharmacogenetics, 13(9), 565-575. doi: 10.1097/01.fpc.0000054122.14659.1e

Mao, L., Jian, C., Changzhi, L., Dan, H., Suihua, H., Wenyi, T., \& Wei, W. (2013). Cytochrome CYP2C19 polymorphism and risk of adverse clinical events in clopidogrel-treated patients: a meta-analysis based on 23,035 subjects. Arch Cardiovasc Dis, 106(10), 517-527. doi: 10.1016/j.acvd.2013.06.055

Matthaei, J., Tzvetkov, M. V., Strube, J., Sehrt, D., Sachse-Seeboth, C., Hjelmborg, J. B., . . . Brockmöller, J. (2016). Heritability of Caffeine Metabolism: Environmental Effects Masking Genetic Effects on CYP1A2 Activity but Not on NAT2. Clin Pharmacol Ther, 100(6), 606616. doi: 10.1002/cpt.444

McDonagh, E. M., Wassenaar, C., David, S. P., Tyndale, R. F., Altman, R. B., Whirl-Carrillo, M., \& Klein, T. E. (2012). PharmGKB summary: very important pharmacogene information for cytochrome P-450, family 2, subfamily A, polypeptide 6. Pharmacogenet Genomics, 22(9), 695-708. doi: 10.1097/FPC.0b013e3283540217

Mega, J. L., Simon, T., Collet, J. P., Anderson, J. L., Antman, E. M., Bliden, K., . . Sabatine, M. S. (2010). Reduced-function CYP2C19 genotype and risk of adverse clinical outcomes among patients treated with clopidogrel predominantly for PCI: a meta-analysis. JAMA, 304(16), 1821-1830. doi: 10.1001/jama.2010.1543

Miksys, S., \& Tyndale, R. F. (2004). The unique regulation of brain cytochrome P450 2 (CYP2) family enzymes by drugs and genetics. Drug Metab Rev, 36(2), 313-333. doi: 10.1081/DMR120034149

Moriyama, B., Obeng, A. O., Barbarino, J., Penzak, S. R., Henning, S. A., Scott, S. A., . . Walsh, T. J. (2016). Clinical Pharmacogenetics Implementation Consortium (CPIC) Guidelines for CYP2C19 and Voriconazole Therapy. Clin Pharmacol Ther. doi: 10.1002/cpt.583 
Mwinyi, J., Hofmann, Y., Pedersen, R. S., Nekvindova, J., Cavaco, I., Mkrtchian, S., \& IngelmanSundberg, M. (2010). The transcription factor GATA-4 regulates cytochrome P4502C19 gene expression. Life Sci, 86(19-20), 699-706. doi: 10.1016/j.lfs.2010.02.021

Nebert, D. W., \& Russell, D. W. (2002). Clinical importance of the cytochromes P450. Lancet, 360(9340), 1155-1162. doi: 10.1016/S0140-6736(02)11203-7

Nelson, D. R., Zeldin, D. C., Hoffman, S. M., Maltais, L. J., Wain, H. M., \& Nebert, D. W. (2004). Comparison of cytochrome P450 (CYP) genes from the mouse and human genomes, including nomenclature recommendations for genes, pseudogenes and alternative-splice variants. Pharmacogenetics, 14(1), 1-18.

Orliaguet, G., Hamza, J., Couloigner, V., Denoyelle, F., Loriot, M. A., Broly, F., \& Garabedian, E. N. (2015). A case of respiratory depression in a child with ultrarapid CYP2D6 metabolism after tramadol. Pediatrics, 135(3), e753-755. doi: 10.1542/peds.2014-2673

Pan, X., Ning, M., \& Jeong, H. (2017). Transcriptional Regulation of CYP2D6 Expression. Drug Metab Dispos, 45(1), 42-48. doi: 10.1124/dmd.116.072249

Pan, Y., Chen, W., Xu, Y., Yi, X., Han, Y., Yang, Q., . . Wang, Y. (2017). Genetic Polymorphisms and Clopidogrel Efficacy for Acute Ischemic Stroke or Transient Ischemic Attack: A Systematic Review and Meta-Analysis. Circulation, 135(1), 21-33. doi: 10.1161/CIRCULATIONAHA.116.024913

Park, S. R., Kong, S. Y., Nam, B. H., Choi, I. J., Kim, C. G., Lee, J. Y., . . . Kim, N. K. (2011). CYP2A6 and ERCC1 polymorphisms correlate with efficacy of S-1 plus cisplatin in metastatic gastric cancer patients. Br J Cancer, 104(7), 1126-1134. doi: 10.1038/bjc.2011.24

Pietarinen, P., Tornio, A., \& Niemi, M. (2016). High Frequency of CYP2D6 Ultrarapid Metabolizer Genotype in the Finnish Population. Basic Clin Pharmacol Toxicol, 119(3), 291-296. doi: $10.1111 /$ bcpt. 12590

Pirmohamed, M., Burnside, G., Eriksson, N., Jorgensen, A. L., Toh, C. H., Nicholson, T., . . EuPact Group. (2013). A randomized trial of genotype-guided dosing of warfarin. NEngl J Med, 369(24), 2294-2303. doi: 10.1056/NEJMoa1311386

Ray, R., Tyndale, R. F., \& Lerman, C. (2009). Nicotine dependence pharmacogenetics: role of genetic variation in nicotine-metabolizing enzymes. $J$ Neurogenet, 23(3), 252-261. doi: 10.1080/01677060802572887

Rettie, A. E., Korzekwa, K. R., Kunze, K. L., Lawrence, R. F., Eddy, A. C., Aoyama, T., . . Trager, W. F. (1992). Hydroxylation of warfarin by human cDNA-expressed cytochrome P-450: a role for P-4502C9 in the etiology of (S)-warfarin-drug interactions. Chem Res Toxicol, 5(1), 54-59.

Sachse, C., Brockmoller, J., Bauer, S., \& Roots, I. (1999). Functional significance of a C-->A polymorphism in intron 1 of the cytochrome P450 CYP1A2 gene tested with caffeine. $\mathrm{Br} J$ Clin Pharmacol, 47(4), 445-449.

Scott, S. A., Sangkuhl, K., Stein, C. M., Hulot, J. S., Mega, J. L., Roden, D. M., . . Shuldiner, A. R. (2013). Clinical Pharmacogenetics Implementation Consortium guidelines for CYP2C19 genotype and clopidogrel therapy: 2013 update. Clin. Pharmacol. Ther., 94(3), 317-323. doi: clpt2013105 [pii]

10.1038/clpt.2013.105

Sibbing, D., Koch, W., Gebhard, D., Schuster, T., Braun, S., Stegherr, J., . . Kastrati, A. (2010). Cytochrome 2C19*17 allelic variant, platelet aggregation, bleeding events, and stent thrombosis in clopidogrel-treated patients with coronary stent placement. Circulation, 121(4), 512-518. doi: 10.1161/CIRCULATIONAHA.109.885194

Somogyi, A. A., Coller, J. K., \& Barratt, D. T. (2015). Pharmacogenetics of opioid response. Clin Pharmacol Ther, 97(2), 125-127. doi: 10.1002/cpt.23

Stage, T. B., Christensen, M. M., Feddersen, S., Beck-Nielsen, H., \& Brøsen, K. (2013). The role of genetic variants in CYP2C8, LPIN1, PPARGC1A and PPARgamma on the trough steady- 
state plasma concentrations of rosiglitazone and on glycosylated haemoglobin A1c in type 2 diabetes. Pharmacogenet Genomics, 23(4), 219-227. doi: 10.1097/FPC.0b013e32835f91fc

Sun, W., Li, Y., Li, J., Zhang, Z., Zhu, W., Liu, W., . . Xu, G. (2015). Variant recurrent risk among stroke patients with different CYP2C19 phenotypes and treated with clopidogrel. Platelets, 26(6), 558-562. doi: 10.3109/09537104.2014.953044

Swen, J. J., Nijenhuis, M., de Boer, A., Grandia, L., Maitland-van der Zee, A. H., Mulder, H., ... Guchelaar, H. J. (2011). Pharmacogenetics: from bench to byte--an update of guidelines. Clin Pharmacol Ther, 89(5), 662-673. doi: 10.1038/clpt.2011.34

Tanii, H., Shitara, Y., \& Horie, T. (2011). Population pharmacokinetic analysis of letrozole in Japanese postmenopausal women. Eur J Clin Pharmacol, 67(10), 1017-1025. doi: 10.1007/s00228-011-1042-3

Tanner, J. A., \& Tyndale, R. F. (2017). Variation in CYP2A6 Activity and Personalized Medicine. $J$ Pers Med, 7(4). doi: 10.3390/jpm7040018

Thompson, E. E., Kuttab-Boulos, H., Witonsky, D., Yang, L., Roe, B. A., \& Di Rienzo, A. (2004). CYP3A variation and the evolution of salt-sensitivity variants. Am J Hum Genet, 75(6), 10591069. doi: $10.1086 / 426406$

Tornio, A., Flynn, R., Morant, S., Velten, E., Palmer, C. N. A., MacDonald, T. M., \& Doney, A. S. F. (2018). Investigating Real-World Clopidogrel Pharmacogenetics in Stroke Using a Bioresource Linked to Electronic Medical Records. Clin Pharmacol Ther, 103(2), 281-286. doi: $10.1002 /$ cpt.780

Turpeinen, M., \& Zanger, U. M. (2012). Cytochrome P450 2B6: function, genetics, and clinical relevance. Drug Metabol Drug Interact, 27(4), 185-197. doi: 10.1515/dmdi-2012-0027

Wang, D., Guo, Y., Wrighton, S. A., Cooke, G. E., \& Sadee, W. (2011). Intronic polymorphism in CYP3A4 affects hepatic expression and response to statin drugs. Pharmacogenomics J, 11(4), 274-286. doi: 10.1038/tpj.2010.28

Wang, H., \& Tompkins, L. M. (2008). CYP2B6: new insights into a historically overlooked cytochrome P450 isozyme. Curr Drug Metab, 9(7), 598-610.

Werk, A. N., \& Cascorbi, I. (2014). Functional gene variants of CYP3A4. Clin Pharmacol Ther, 96(3), 340-348. doi: 10.1038/clpt.2014.129

Werk, A. N., Lefeldt, S., Bruckmueller, H., Hemmrich-Stanisak, G., Franke, A., Roos, M., . . . Renders, L. (2014). Identification and characterization of a defective CYP3A4 genotype in a kidney transplant patient with severely diminished tacrolimus clearance. Clin Pharmacol Ther, 95(4), 416-422. doi: 10.1038/clpt.2013.210

Westlind-Johnsson, A., Hermann, R., Huennemeyer, A., Hauns, B., Lahu, G., Nassr, N., . . . von Richter, O. (2006). Identification and characterization of CYP3A4*20, a novel rare CYP3A4 allele without functional activity. Clin Pharmacol Ther, 79(4), 339-349. doi: 10.1016/j.clpt.2005.11.015

Wilke, R. A., Moore, J. H., \& Burmester, J. K. (2005). Relative impact of CYP3A genotype and concomitant medication on the severity of atorvastatin-induced muscle damage. Pharmacogenet Genomics, 15(6), 415-421.

Willrich, M. A., Hirata, M. H., Genvigir, F. D., Arazi, S. S., Rebecchi, I. M., Rodrigues, A. C., . . Hirata, R. D. (2008). CYP3A53A allele is associated with reduced lowering-lipid response to atorvastatin in individuals with hypercholesterolemia. Clin Chim Acta, 398(1-2), 15-20. doi: 10.1016/j.cca.2008.07.032

Vo, T. T., \& Varghese Gupta, S. (2016). Role of Cytochrome P450 2B6 Pharmacogenomics in Determining Efavirenz-Mediated Central Nervous System Toxicity, Treatment Outcomes, and Dosage Adjustments in Patients with Human Immunodeficiency Virus Infection. Pharmacotherapy, 36(12), 1245-1254. doi: 10.1002/phar.1852 
Yano, J. K., Hsu, M. H., Griffin, K. J., Stout, C. D., \& Johnson, E. F. (2005). Structures of human microsomal cytochrome P450 2A6 complexed with coumarin and methoxsalen. Nat Struct Mol Biol, 12(9), 822-823. doi: 10.1038/nsmb971

Yasar, U., Lundgren, S., Eliasson, E., Bennet, A., Wiman, B., de Faire, U., \& Rane, A. (2002). Linkage between the CYP2C8 and CYP2C9 genetic polymorphisms. Biochem Biophys Res Commun, 299(1), 25-28.

Zanger, U. M., \& Klein, K. (2013). Pharmacogenetics of cytochrome P450 2B6 (CYP2B6): advances on polymorphisms, mechanisms, and clinical relevance. Front Genet, 4, 24. doi: 10.3389 /fgene.2013.00024

Zanger, U. M., \& Schwab, M. (2013). Cytochrome P450 enzymes in drug metabolism: regulation of gene expression, enzyme activities, and impact of genetic variation. Pharmacol Ther, 138(1), 103-141. doi: 10.1016/j.pharmthera.2012.12.007

Zanger, U. M., Turpeinen, M., Klein, K., \& Schwab, M. (2008). Functional pharmacogenetics/genomics of human cytochromes P450 involved in drug biotransformation. Anal Bioanal Chem, 392(6), 1093-1108. doi: 10.1007/s00216-008-2291-6

Zhang, H. F., Wang, H. H., Gao, N., Wei, J. Y., Tian, X., Zhao, Y., . . . Qiao, H. L. (2016). Physiological Content and Intrinsic Activities of 10 Cytochrome P450 Isoforms in Human Normal Liver Microsomes. $J$ Pharmacol Exp Ther, 358(1), 83-93. doi: 10.1124/jpet.116.233635

Zhao, F., Wang, J., Yang, Y., Wang, X., Shi, R., Xu, Z., . . Zhang, G. (2008). Effect of CYP2C19 genetic polymorphisms on the efficacy of proton pump inhibitor-based triple therapy for Helicobacter pylori eradication: a meta-analysis. Helicobacter, 13(6), 532-541. doi: 10.1111/j.1523-5378.2008.00643.x

Zhou, S. F. (2008). Drugs behave as substrates, inhibitors and inducers of human cytochrome P450 3A4. Curr Drug Metab, 9(4), 310-322.

Zhou, S. F., Wang, B., Yang, L. P., \& Liu, J. P. (2010). Structure, function, regulation and polymorphism and the clinical significance of human cytochrome P450 1A2. Drug Metab Rev, 42(2), 268-354. doi: 10.3109/03602530903286476

Zhou, Y., Ingelman-Sundberg, M., \& Lauschke, V. M. (2017). Worldwide Distribution of Cytochrome P450 Alleles: A Meta-analysis of Population-scale Sequencing Projects. Clin Pharmacol Ther, 102(4), 688-700. doi: 10.1002/cpt.690

Zhu, A. Z., Cox, L. S., Nollen, N., Faseru, B., Okuyemi, K. S., Ahluwalia, J. S., . . Tyndale, R. F. (2012). CYP2B6 and bupropion's smoking-cessation pharmacology: the role of hydroxybupropion. Clin Pharmacol Ther, 92(6), 771-777. doi: 10.1038/clpt.2012.186 